MANAGEMENT AND ADMINISTRATIVE PROFESSIONAL REVIEW

\section{Editora Científica: Dra. Cibele B. Martins}

Avaliação: Double Blind Review pelo SEER/OJS

Revisão: Gramatical, normativa e de formatação

Data de recebimento do artigo: 3-12-2017

Data de aceite do artigo: $26-1-2018$

DOI: http://dx.doi.org/10.7769/gesec.v9i1.763

\title{
Atuação do secretário executivo na gestão universitária pública: o estado do conhecimento sobre a questão
}

\section{Fernanda Geremias Leal}

Doutoranda em Administração na Universidade do Estado de Santa Catarina (UDESC). Secretáriaexecutiva na Secretaria de Relações Internacionais da UFSC. E-mail: fernanda.leal @ufsc.br (Brasil).

\author{
Stefani de Souza \\ Mestra Profissional em Administração Universitária pela Universidade Federal de Santa Catarina \\ (UFSC). Secretária-executiva na Direção do Centro Tecnológico da UFSC. \\ E-mail: stefani.souza@ufsc.br (Brasil). \\ Kátia Denise Moreira \\ Doutoranda em Administração na Universidade Federal de Santa Catarina (UFSC). Mestra \\ Profissional em Administração pela UFSC. Assessora do Gabinete da Reitoria UFSC. \\ E-mail: katia.denise@ufsc.br (Brasil).
}

\section{RESUMO}

O objetivo do presente estudo é apresentar o estado do conhecimento sobre a atuação do secretário executivo na gestão das Instituições Federais de Ensino Superior (IFES). A partir de critérios de revisão sistemática de literatura, desenvolve-se uma pesquisa bibliográfica em artigos de periódicos e trabalhos stricto sensu sobre o tema. A literatura abrangida pelo recorte da pesquisa, constituída de dez artigos e seis dissertações, permite inferir que o interesse teórico-empírico sobre a atuação do secretário executivo nas IFES articula-se em torno de questões que, juntas, fornecem uma visão panorâmica do tema: as motivações para o ingresso nesse contexto; a forma de inserção; o perfil e o panorama dos ocupantes do cargo; as condições de trabalho; as competências e as contribuições em unidades administrativas e acadêmicas. Embora os estudos analisados apontem para diversas dificuldades inerentes à gestão do cargo e induzam à conclusão de que muitos secretários executivos não são bem aproveitados pelas IFES, eles também permitem inferir que esses profissionais se destacam e são reconhecidos por sua produtividade, capacidade de interpretação de situações, intervenção e tomada de decisão, entre outros aspectos relevantes ao aperfeiçoamento da gestão universitária pública.

PALAVRAS-CHAVE: Secretário executivo. Gestão universitária. Instituições Federais de Ensino Superior. 


\title{
Executive assistants in the Brazilian public university management: the state of knowledge on the subject
}

\begin{abstract}
This study aims to present the state of knowledge about the role of the executive assistant in the management of Higher Education Federal Institutions (IFES, in Portuguese). Based on systematic literature review criteria, we developed a bibliographic research in journal articles, thesis and dissertations on the subject. The literature covered by the study, ten articles and six dissertations, allows us to infer that the theoretical-empirical interest in the role of the executive assistant in the IFES articulates around issues that together provide a panoramic view of the subject: the motivations for their entry in this context; their form of insertion; their profile and panorama; their working conditions; their competencies and their contributions to administrative and academic units. Although the studies point to several difficulties inherent to the management of this position and lead to the conclusion that IFES do not take the most of many executive secretaries, they also allow us to infer that these professionals are recognized for their productivity, capacity of interpreting situations, intervention and decision making, among other relevant aspects for the improvement of the Brazilian public university management.
\end{abstract}

KEYWORDS: Executive Secretariat. University management. Higher Education Federal Institutions.

\section{Como referenciar em APA:}

Leal, F. G., Souza, S., \& Moreira, K. D. (2018). Atuação do secretário executivo na gestão universitária pública: o estado do conhecimento sobre a questão. R.G.Secr.,GESEC, 9(1). doi: http://dx.doi.org/10.7769/gesec.v9i1.763

\section{Como referenciar em ABNT:}

LEAL, F. G.; SOUZA, S.; MOREIRA, K. D. Atuação do secretário executivo na gestão universitária pública: o estado do conhecimento sobre a questão. R.G.Secr.,GESEC, v. 9, n. 1, 2018. doi: http://dx.doi.org/10.7769/gesec.v9i1.763
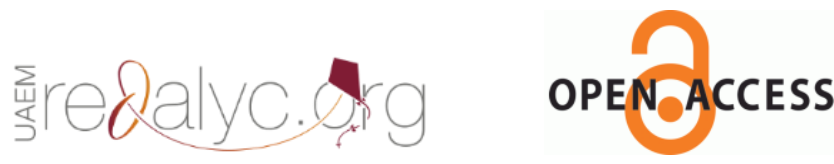

R.G. Secr., GESEC, São Paulo, v. 9, n. 1, p 66-89, jan./abr. 2018. 


\section{Introdução}

O secretariado executivo contemplou, nos últimos anos, um crescimento significativo em termos de produção científica, na forma de artigos de eventos e de periódicos, livros, dissertações e teses. Alguns dos trabalhos desenvolvidos (Maçaneiro \& Kuhl, 2013; Muller \& Sanches, 2014; Durante \& Pontes, 2015; Sanches, Schmidt \& Dias, 2014; Durante, 2016; Monteiro, Crotti \& Santos, 2016) tratam especificamente do estado do conhecimento nesse campo de pesquisa e suscitam insights importantes em relação aos fenômenos que o interessam.

Questões relacionadas à atuação do profissional de secretariado integram o núcleo dos interesses correntes. Nesse domínio, há estudos que tratam dos diferentes ambientes organizacionais em que ele se insere, tais como a esfera pública brasileira e, especificamente, as Instituições Federais de Ensino Superior (IFES). A estruturação da literatura sobre a atuação do secretário executivo na gestão universitária das IFES iniciou-se após a abertura de concursos públicos para o cargo no âmbito dessas instituições, em 2005. Desde então, pesquisas sobre o tema foram desenvolvidas, constituindo-se, em sua maioria, como estudos de caso em IFES específicas.

Diante do entendimento de que a constituição do secretariado executivo como campo científico também implica na necessidade de analisar, refletir e discutir sobre o que está sendo produzido, o objetivo deste estudo é apresentar o estado do conhecimento sobre a atuação do secretário executivo na gestão das IFES. Os objetivos específicos, por sua vez, são: a) contextualizar os aspectos gerais dos trabalhos localizados; b) identificar seus fundamentos teórico-empíricos; c) fazer um balanço da literatura, com foco nas suas principais contribuições. Em termos metodológicos, o estudo tem natureza qualitativa e foi desenvolvido por meio de pesquisa bibliográfica em artigos de periódicos e trabalhos stricto sensu sobre o tema, segundo critérios de revisão sistemática de literatura.

Almeja-se que o estudo contribua para a análise das perspectivas de atuação do secretário executivo nesse contexto - sobretudo considerando-se a recente vedação de abertura de concurso público e de provimento do cargo, por meio do Decreto n. 9.262, de 9 de janeiro de 2018 (Brasil, 2018) - assim como para o aperfeiçoamento da gestão universitária pública. Complementarmente, que aponte as possibilidades de pesquisas futuras sobre o tema, uma vez que sintetiza as contribuições dos trabalhos existentes. Nesse aspecto, cabe pontuar 
que até o presente momento inexistem estudos de revisão de literatura sobre a atuação desse profissional em nichos organizacionais específicos.

\section{Referencial Teórico}

A presente seção apresenta um panorama sobre a gestão universitária no contexto das IFES e a inserção do profissional de secretariado executivo nesse ambiente.

\subsection{Gestão universitária}

As instituições universitárias estão entre as mais complexas organizações sociais (Etzioni, 1967). Tratam-se de ambientes altamente institucionalizados e pluralísticos, confrontados por uma série de ordens normativas e constituídos por mais de uma lógica cultural, com diferentes prescrições para a ação (Seeber et al., 2016). Conjunturas contemporâneas, como a expansão da ciência e da tecnologia e a instituição da "economia do conhecimento", que centralizam o papel da educação no desenvolvimento da humanidade, provocam tensões e contribuem para esse cenário (Kim, 2017).

As Instituições Federais de Ensino Superior (IFES), objeto deste estudo, integram o sistema federal de ensino (Brasil, 2006). As universidades, inseridas nesse conjunto, caracterizam-se como "instituições pluridisciplinares de formação dos quadros profissionais de nível superior, de pesquisa, de extensão e de domínio e cultivo do saber humano" (Brasil, 1996). Autores como Souza I. M (2010) e Meyer Júnior e Lopes (2015) sustentam que suas principais características são a ambiguidade de objetivos, a tecnologia indefinida, os grupos de interesse, o poder compartilhado e a imensurabilidade do valor agregado, aspectos que contribuem para a complexidade desses ambientes e constituem barreiras à adoção de práticas tradicionais de gestão. Em decorrência dessas especificidades, tais ambientes demandam abordagens de gestão próprias, ainda não disponíveis devido à incompatibilidade entre a racionalidade implícita em abordagens gerenciais tradicionais e as características peculiares dessas instituições (Meyer Júnior \& Lopes, 2015).

Nessa direção, autores como Souza I. M. (2010) e Meyer Júnior e Lopes (2015) consideram que, dada a inexistência de uma teoria pronta e consolidada de gestão universitária, métodos, abordagens e práticas das teorias tradicionais devem ser ajustados, pelos gestores universitários, às especificidades das instituições acadêmicas, a fim de que eles 
Leal, F. G., Souza, S., \& Moreira, K. D. (2018).

possam tomar boas decisões, que não estarão necessariamente respaldadas nos modelos racionais de gestão importados do setor empresarial.

\subsection{O secretário executivo na gestão universitária pública}

Entre os cargos de Servidores Técnico-Administrativos em educação (STAEs) de nível superior das IFES está o de secretário executivo, criado durante o processo de enquadramento previsto no Plano Único de Classificação e Retribuição de Cargos e Empregos (PUCRCE), em 1987. Naquela ocasião, os STAEs que desempenhavam as funções típicas de secretário executivo e que possuíam diploma de nível superior, independente da área de conhecimento, foram beneficiados pela legislação, passando a ocupar o cargo por meio da obtenção do registro profissional. Após a implantação do Plano de Carreira dos Cargos Técnicoadministrativos em Educação (PCCTAE), em 2005, autorizou-se a realização de concursos públicos para o cargo no plano das IFES (Brasil, 2005; Leal, 2014). Entre 2010 e 2014, pelo menos 57 concursos foram realizados por 48 IFES (Leal, Silva \& Dalmau, 2014) e, no segundo semestre de 2016, 1.738 secretários-executivos já atuavam nessas instituições: 1.690 nas universidades e 48 nos institutos federais (Souza, S. 2017).

De acordo com a Lei n. ${ }^{\circ}$ 11.091/2005, que regulamenta o PPCTAE, o requisito para ingresso no cargo de secretário executivo é "curso Superior em Letras ou Secretário [sic] Executivo Bilíngue" (Brasil, 2005). Com o Ofício Circular n. ${ }^{\circ}$ 15/2005/CGGP/SAA/SE/MEC (MEC, 2005), acrescentou-se como requisito a habilitação profissional. Portanto, além da aprovação no concurso público, exige-se para a posse a apresentação de diploma de curso superior em Secretariado e de habilitação profissional nos termos das leis que regem a profissão (Leal, Silva \& Dalmau, 2014).

As atribuições prescritas a esse profissional no domínio das IFES, descritas no Ofício Circular n. 15/2005, contemplam o assessoramento de direções; o atendimento de pessoas; o gerenciamento de informações; a elaboração de documentos; o controle de correspondências; a organização de eventos e viagens; a supervisão de equipes de trabalho e o arquivamento de documentos, além de outras tarefas de mesma natureza e nível de complexidade, relacionadas ao seu ambiente organizacional (MEC, 2005). Como Leal e Moraes (2017) evidenciam, a quantidade significativa de secretários executivos nas IFES, associada às mudanças observadas no perfil profissiográfico secretarial das últimas décadas e à ausência de 
conhecimentos empíricos sobre sua atuação nessas instituições suscitaram o desenvolvimento de trabalhos acadêmicos/científicos sobre o tema nos últimos anos.

\section{Percurso Metodológico}

Esta seção expõe o caminho metodológico percorrido para o desenvolvimento da pesquisa.

\subsection{Caracterização da pesquisa}

Este estudo tem natureza qualitativa e descritiva e foi desenvolvido por meio de pesquisa bibliográfica em artigos de periódicos e trabalhos stricto sensu sobre a atuação do secretário executivo nas IFES, segundo critérios de revisão sistemática de literatura (Sampaio \& Mancini, 2007; Stake, 2011; Pérez, 2015; Siekierski \& Lima, 2016). A revisão de literatura constitui-se como evidência de que se analisou de forma suficiente os materiais teóricos e as publicações de pesquisas com bases conceituais sobre o tema de interesse. Assim, deve ser metódica, explícita e passível de reprodução (Sampaio \& Mancini, 2007; Stake, 2011). Quando desenvolvida segundo tais critérios, a pesquisa bibliográfica funciona como um refinamento do "estado do conhecimento" sobre determinado fenômeno. Portanto, ajuda "a compreender os problemas antes e a interpretar as descobertas posteriormente" (Stake, 2011, p. 118), assim como, explicam Sampaio e Mancini (2007), auxilia no desenvolvimento de projetos, visto que direciona novos caminhos para investigações e identifica métodos de pesquisa utilizados em determinado campo.

\subsection{Procedimentos de levantamento bibliográfico: coleta dos dados}

Um estudo de revisão sistemática requer a definição de uma pergunta clara e de uma estratégia de busca, com critérios de inclusão e exclusão e, sobretudo, a análise criteriosa da qualidade da literatura selecionada (Sampaio \& Mancini, 2007). A pergunta que norteou esta etapa foi: "como a literatura científica brasileira aborda a atuação do secretário executivo nas IFES?”. Com vistas a atender aos critérios de qualidade almejados, optou-se por restringir a investigação a artigos de periódicos e trabalhos stricto sensu. 
Para fins de localização dos artigos sobre o tema de interesse, foram consultados os cinco periódicos brasileiros que mais publicam no campo secretarial conforme busca exploratória realizada pelas autoras. São eles: Revista de Gestão e Secretariado; Capital Científico; Secretariado Executivo em Revista; Revista Expectativa e Fazu em Revista (Dias, Schmidt \& Sanches, 2014). Os artigos foram identificados por meio de consultas em todas as edições desses periódicos (desde 2008, quando o primeiro artigo foi publicado). Isso porque, dos cinco selecionados, somente dois (Revista de Gestão e Secretariado e Capital Científico) estão indexados às bases de dados mais reconhecidas.

Para incluir artigos de outros periódicos, realizou-se uma busca complementar na base Spell, pelo termo "secretariado". Das buscas diretas nos periódicos emergiram nove artigos relacionados à atuação do secretário executivo nas IFES, enquanto que da busca na base Spell, apenas um, totalizando dez artigos.

Em relação aos trabalhos stricto sensu, realizou-se uma busca sistemática no Portal de Teses e Dissertações da Capes, sem restrição temporal, pelos termos "secretariado" (131 resultados) e "secretariado executivo" (31 resultados). Entre esses, foram localizadas cinco dissertações relacionadas ao tema e nenhuma tese. Uma sexta dissertação sobre o assunto, recentemente defendida e, portanto, ainda não disponível na base, também foi incluída à análise. As buscas sistemáticas foram realizadas entre maio e junho de 2017. O corpus da investigação constituiu-se de dezesseis trabalhos, sendo dez artigos de periódicos e seis dissertações, que foram lidos na íntegra para fins de análise.

\subsection{Protocolo de pesquisa: análise dos dados}

Os dezesseis trabalhos contemplados pelo recorte da pesquisa foram analisados em torno de três dimensões: 1 . aspectos gerais; 2 . fundamentos teórico-empíricos e 3. balanço da literatura. A Tabela 1 explicita os indicadores que guiaram a análise de cada dimensão.

Tabela 1 - Dimensões e indicadores do protocolo de pesquisa.

\begin{tabular}{|l|l|}
\hline Dimensões & Indicadores \\
\hline \multirow{3}{*}{ Aspectos gerais } & 1. Ano de publicação \\
& 2. Periódico de veiculação \\
\hline \multirow{3}{*}{ Fundamentos } & 3. Região, instituição e programa de pós-graduação de origem dos trabalhos \\
\hline teórico-empíricos & 1. Tipo de trabalho e caminho metodológico percorrido \\
& 2. Instituições analisadas nos estudos de caso \\
\hline Balanço da literatura & 3. Temas/objetos de interesse \\
\hline Fonte: Elaborada pelos autores & 4. Principais perspectivas teóricas que fundamentaram as análises \\
\hline
\end{tabular}

Fonte: Elaborada pelos autores (2017).

R.G. Secr., GESEC, São Paulo, v. 9, n. 1, p 65-89, jan./abr. 2018. 
A definição dos indicadores foi feita com base em outros trabalhos de revisão de literatura desenvolvidos nas ciências sociais, adequados ao campo de interesse. Os dados foram sistematizados em tabelas, para serem visualizados em perspectiva ampla e comparativa.

\section{Análises e Considerações}

Os dezesseis estudos selecionados foram analisados a partir dos indicadores adotados, sendo os resultados contextualizados nas seções subsequentes.

\subsection{Aspectos gerais dos trabalhos}

\section{Ano de publicação}

O interesse científico na atuação do secretário executivo no contexto das IFES é bastante incipiente; iniciou-se há aproximadamente uma década, com a publicação do primeiro artigo no tema. A primeira dissertação, por sua vez, foi publicada em 2010. Em ambos os casos, a maior incidência de trabalhos ocorreu em 2014. Os Gráficos 1 e 2 ilustram, respectivamente, a distribuição por ano dos artigos e das dissertações incluídos no recorte da pesquisa.

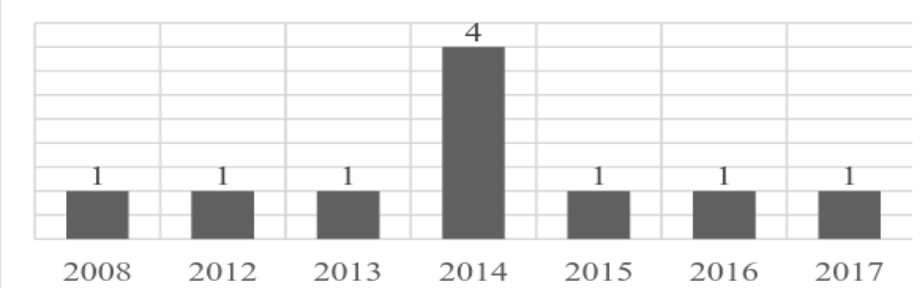

Gráfico 1 - Distribuição por ano dos artigos sobre o tema. Fonte: Elaborado pelos autores (2017). 


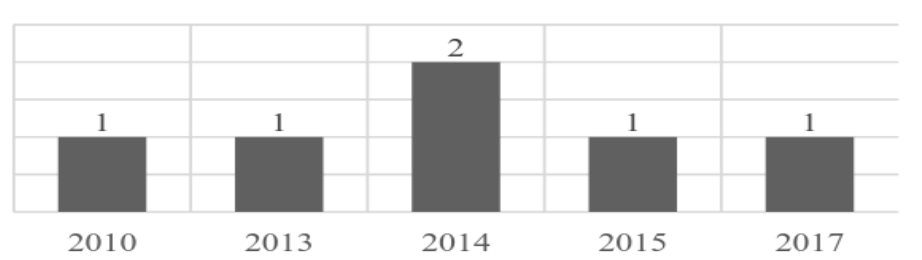

Gráfico 2 - Distribuição por ano das dissertações sobre o tema. Fonte: Elaborado pelos autores (2017).

Dois fatores parecem justificar o incipiente interesse no tema. Por um lado, a inserção do secretário executivo nas IFES mediante concurso público ocorreu somente em 2005, com a implementação do PCCTAE (Brasil, 2005). Por outro, a própria estruturação do secretariado executivo como campo de pesquisa é recente: iniciou-se nos anos de 2000, com uma série de iniciativas voltadas a este fim, que culminaram no aumento significativo da produção científica, nas formas de artigos, livros, dissertações e teses (Martins et al., 2015; Dias, Schmidt \& Sanches, 2016; Durante, 2016).

\section{Periódico de veiculação}

A grande maioria dos artigos sobre a atuação do secretário executivo no contexto das IFES foi publicada no periódico Revista de Gestão e Secretariado (GeSec), um projeto editorial resultante "de uma parceria de pesquisadores pertencentes a diversos núcleos e grupos de estudos de secretariado existentes em universidades e no Comitê Estratégico do Sindicato das Secretárias e Secretários do Estado de São Paulo", atualmente classificado como Qualis B2 em Administração no estrato Capes (GeSec, 2017). Outros periódicos que publicaram artigos sobre o tema foram: Secretariado Executivo em Revista, Revista do Secretariado Executivo e Revista de Ciências da Administração, como demonstra o Gráfico 3.

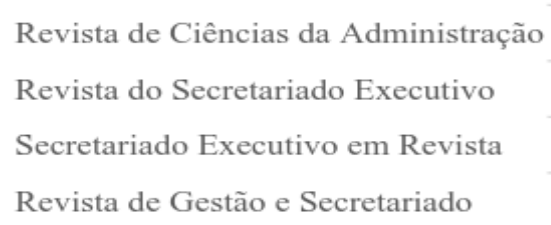

Gráfico 3 - Periódicos com publicações sobre o tema. Fonte: Elaborado pelos autores (2017).

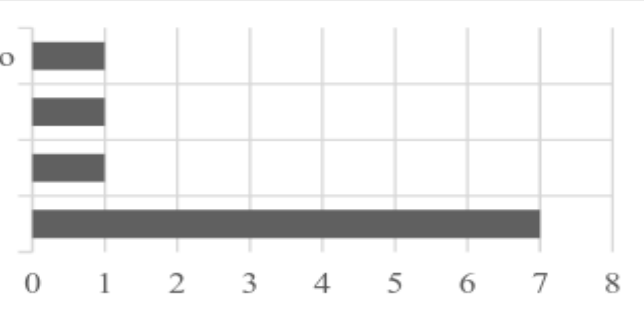

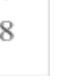




\section{Região, instituição e programa de pós-graduação de origem dos trabalhos}

A análise permitiu evidenciar que uma grande concentração de estudos é proveniente da região Sul do Brasil (Santa Catarina e Rio Grande do Sul). Outras regiões com publicações sobre o tema são o Sudeste (São Paulo e Minas Gerais), o Nordeste (Ceará) e o Centro-oeste (Distrito Federal). Dois artigos (Oliveira, Minetti \& Oliveira, 2012; Oliveira et al., 2016) foram desenvolvidos por meio de cooperação entre autores de diferentes regiões (Sul e Sudeste), como ilustra o Gráfico 4.

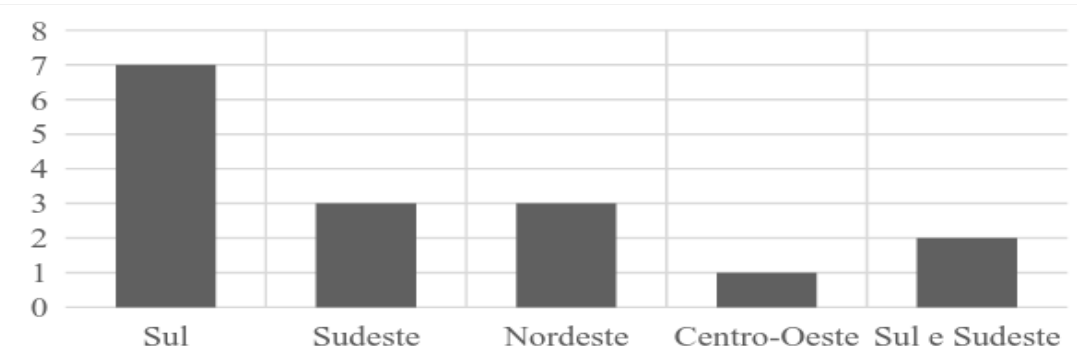

Gráfico 4 - Regiões com publicações sobre o tema

Fonte: Elaborado pelos autores (2017).

Quanto às instituições em que os trabalhos foram desenvolvidos, observa-se que a Universidade Federal de Santa Catarina (UFSC) é a mais recorrente, seguida da Universidade Federal do Ceará (UFC) e da Universidade Federal de Viçosa (UFV). Três trabalhos foram desenvolvidos por meio de cooperação entre autores de diferentes instituições: Universidade Federal de Santa Maria (UFSM) e UFV (Oliveira, Minetti \& Oliveira, 2012; Oliveira et al., 2016); UFSM e Universidade Federal de Brasília (UnB) (Oliveira \& Moraes, 2014). Um aspecto interessante é que parte significativa dos autores dos trabalhos é também ocupante do cargo de secretário executivo nas IFES, fato que pode justificar parte do seu interesse no tema. O Gráfico 5 demonstra a incidência de trabalhos por instituição.

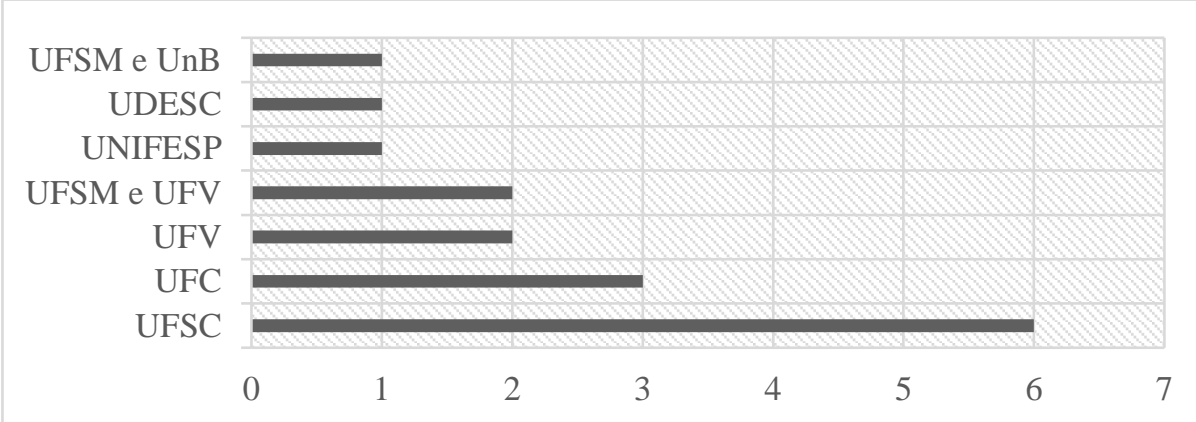

R.G. Secr., GESEC, São Paulo, v. 9, n. 1, p 66-89, jan./abr. 2018. 
Leal, F. G., Souza, S., \& Moreira, K. D. (2018).

Gráfico 5 - Instituições com publicações sobre o tema Fonte: Elaborado pelos autores (2017).

Finalmente, quanto aos programas de pós-graduação em que as dissertações foram desenvolvidas, evidenciou-se uma concentração em cursos de mestrado profissional, nas áreas de Administração Universitária e de Políticas Públicas (Ferreira, 2011; Pinheiro, 2013; Sousa, 2014; Raviani, 2015; Souza, S. 2017). Uma única dissertação provém de curso de mestrado acadêmico, na área de Administração (Leal, 2014). O Gráfico 6 explicita os títulos dos programas de pós-graduação e as respectivas instituições que originaram tais trabalhos.

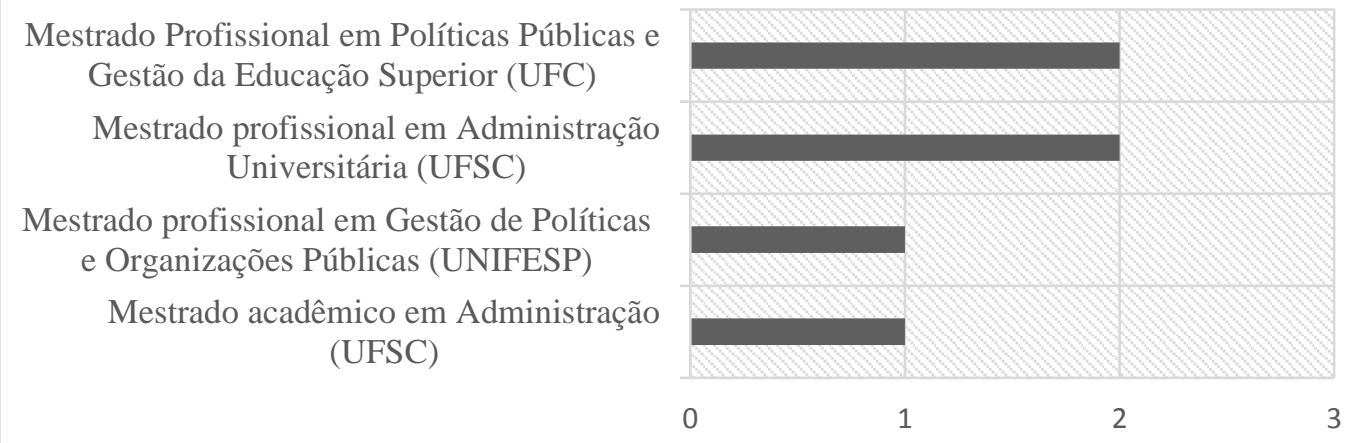

Gráfico 6 - Programas de pós-graduação e instituições com dissertações sobre o tema. Fonte: Elaborado pelos autores (2017).

Cabe pontuar, aqui, que o Secretariado Executivo ainda não dispõe de pós-graduação stricto sensu no Brasil, de modo que os trabalhos sobre o tema são desenvolvidos em cursos de áreas afins.

\subsection{Fundamentos teórico-empíricos dos trabalhos}

\section{Tipos de trabalho e caminhos metodológicos percorridos}

A maior parte dos trabalhos considerados pelo recorte da pesquisa desenvolveu-se em uma perspectiva qualitativa - embora alguns tenham contemplado abordagens mistas - e abrangeu a coleta de dados empíricos por meio de pesquisa de campo, os quais foram acessados principalmente por questionários e entrevistas semiestruturadas. Nesses casos, os sujeitos da pesquisa foram, em sua maioria, os próprios ocupantes do cargo (Oliveira, Minetti \& Oliveira, 2012; Pinheiro 2013; Sousa, 2014; Leal, 2014; Leal \& Dalmau, 2014; Souza, S. 
2017), bem como: os gestores das IFES (chefias dos secretários executivos e/ou representantes do setor de gestão de pessoas e/ou gestores de setores considerados como “unidades-chave") (Pinheiro, 2013; Leal \& Fiates, 2013; Leal; 2014; Leal \& Dalmau, 2014; Raviani, 2015; Souza, S. 2017); egressos do curso de Secretariado Executivo (Faria \& Silveira, 2015); coordenadoria do curso de secretariado executivo (Leal, 2014; Leal \& Dalmau, 2014) e representantes de órgãos da classe (Leal, 2014; Leal \& Dalmau, 2014). As pesquisas bibliográfica e documental também foram centrais ao desenvolvimento das análises.

A Tabela 2 apresenta os documentos explorados.

Tabela 2: Documentos analisados pelos trabalhos sobre a atuação do secretário executivo nas IFES

\begin{tabular}{|c|c|}
\hline Documento analisado & Autores \\
\hline Descrição do cargo de secretário executivo nas IFES & $\begin{array}{l}\text { - Ferreira (2011); Sousa (2014); Leal (2014); } \\
\text { Leal \& Dalmau (2014); Leal \& Moraes } \\
\text { (2016); Raviani (2015); Souza, S. (2017) }\end{array}$ \\
\hline $\begin{array}{l}\text { Editais e/ou provas de concursos públicos para o cargo de } \\
\text { secretário executivo nas IFES }\end{array}$ & $\begin{array}{l}\text { - Leal (2014); Leal, Silva \& Dalmau (2014); } \\
\text { Nunes (2014); Oliveira \& Moraes (2014); } \\
\text { Faria \& Silveira (2015); Oliveira et al. } \\
(2016)\end{array}$ \\
\hline $\begin{array}{l}\text { Legislação referente à profissão de secretário executivo (leis de } \\
\text { regulamentação, descrição do cargo na Classificação Brasileira } \\
\text { de Ocupações) e aos cargos dos TAEs }\end{array}$ & $\begin{array}{l}\text { - Leal (2014); Leal \& Dalmau (2014); Sousa } \\
\text { (2014); Raviani (2015); Leal \& Moraes } \\
\text { (2017); Souza (2017) }\end{array}$ \\
\hline $\begin{array}{l}\text { Sítios das IFES; dados de Sistemas Institucionais, Planos } \\
\text { Institucionais e relatórios da área de Gestão de Pessoas da } \\
\text { Instituição }\end{array}$ & $\begin{array}{l}\text { - Raviani (2015); Oliveira \& Moraes (2014); } \\
\text { Souza, S. (2017) }\end{array}$ \\
\hline $\begin{array}{l}\text { Diretrizes Curriculares Nacionais para os cursos de secretariado } \\
\text { executivo; grades curriculares dos cursos de secretariado } \\
\text { executivo das universidades públicas federais e estaduais; Plano } \\
\text { Político Pedagógico de curso de secretariado executivo }\end{array}$ & $\begin{array}{l}\text { - Ferreira (2011); Pinheiro (2013); Leal \& } \\
\text { Dalmau (2014); Sousa (2014); Raviani } \\
\text { (2015); Oliveira et al. (2016); Leal \& } \\
\text { Moraes (2017) }\end{array}$ \\
\hline $\begin{array}{l}\text { Conteúdos programáticos de capacitações/eventos de } \\
\text { associações de educação superior internacional }\end{array}$ & • Leal \& Moraes (2016) \\
\hline Currículos Lattes & - Oliveira \& Moraes (2014) \\
\hline
\end{tabular}

Fonte: Elaborada pelos autores (2017).

\section{Instituições analisadas nos estudos de caso}

As pesquisas analisadas constituem-se, em sua maioria, como estudos de caso em IFES específicas. As duas instituições mais investigadas empiricamente, sobre as quais foram desenvolvidos tanto artigos quanto dissertações, são a Universidade Federal do Ceará (UFC) (Custódio, Ferreira \& Silva, 2008; Ferreira, 2011; Pinheiro, 2013) e a Universidade Federal de Santa Catarina (UFSC) (Leal \& Fiates, 2013; Leal, 2014; Leal \& Dalmau, 2014; Souza, S. 2017). Ambas as instituições contemplam o curso de secretariado executivo em sua estrutura. 
Leal, F. G., Souza, S., \& Moreira, K. D. (2018).

No caso da UFSC, sabe-se que a maioria dos ocupantes do cargo graduou-se na própria instituição (Leal, 2014; Souza, S. 2017). Outras instituições pesquisadas foram a UFV (Faria \& Silveira, 2015), a Universidade Federal de Itajubá (Unifei) (Oliveira, Minetti \& Oliveira, 2012) e a Universidade Federal de Santa Maria (UFSM) (Oliveira \& Moraes, 2014). Um dos trabalhos ainda se caracteriza como estudo de casos múltiplos: Raviani (2015) analisou as competências individuais dos secretários executivos no contexto das três universidades públicas federais do estado de São Paulo: Universidade Federal do ABC (UFABC), Universidade Federal de São Paulo (UNIFESP) e Universidade Federal de São Carlos (UFSCar).

Os demais trabalhos empíricos se voltaram à exploração de um quadro mais amplo da atuação do secretário executivo nesse contexto. Sousa (2014), por exemplo, aplicou questionários a secretários executivos de doze IFES, de todas as regiões do Brasil. Nunes (2014) buscou dados em editais em instituições como Instituto Federal de Educação, Ciência e Tecnologia da Paraíba (IFPB); Instituto Federal de Educação, Ciência e Tecnologia de Pernambuco (IFPE); Universidade de Brasília (UnB) e Universidade Federal do Estado do Rio de Janeiro (UNIRIO). Já Faria e Silveira (2015) aplicaram questionários aos egressos do Curso de Secretariado Executivo da UFV que foram aprovados em concurso público nas IFES de Minas Gerais e na UnB, no Distrito Federal. Leal, Silva e Dalmau (2014), por sua vez, analisaram as provas dos concursos públicos realizados por 48 IFES para o cargo.

\section{Temas/objetos de interesse}

Os trabalhos analisados abordaram a atuação do secretário executivo nas IFES em relação a diferentes fenômenos. A Tabela 3 sintetiza os temas explorados:

Tabela 3: Temas/Objetos explorados nas publicações sobre o tema

\begin{tabular}{|l|l|}
\hline Tema/Objeto de interesse & Autores \\
\hline $\begin{array}{l}\text { Os fatores que influenciam secretários executivos a ingressarem } \\
\text { no cargo nas IFES }\end{array}$ & $\bullet$ Faria \& Silveira, 2015 \\
\hline $\begin{array}{l}\text { Os concursos públicos para o provimento do cargo de secretário } \\
\text { executivo nas IFES }\end{array}$ & $\begin{array}{l}\text { Leal, Silva \& Dalmau, 2014; Nunes, 2014; } \\
\text { Oliveira } \text { et al., 2016 }\end{array}$ \\
\hline $\begin{array}{l}\text { O perfil e o panorama do cargo de secretário executivo nas } \\
\text { IFES }\end{array}$ & $\begin{array}{l}\text { Oliveira \& Moraes, 2014; Sousa, 2014; } \\
\text { Souza, 2017 }\end{array}$ \\
\hline $\begin{array}{l}\text { As condições e a qualidade de vida no trabalho do secretário } \\
\text { executivo de IFES }\end{array}$ & $\begin{array}{l}\text { Oliveira, Minetti \& Oliveira, 2012; } \\
\text { Pinheiro, 2013 }\end{array}$ \\
\hline $\begin{array}{l}\text { As competências secretariais requeridas pelas IFES } \\
\text { Leal, 2014; Raviani, 2015 }\end{array}$ \\
\hline $\begin{array}{l}\text { A atuação e as contribuições do secretário executivo em } \\
\text { unidades administrativas e acadêmicas de IFES }\end{array}$ & $\begin{array}{l}\text { Custódio, Ferreira \& Silva, 2008; Ferreira, } \\
\text { 2010; Leal \& Moraes, 2017 }\end{array}$ \\
\hline
\end{tabular}

Fonte: Elaborada pelos autores (2017).

R.G. Secr., GESEC, São Paulo, v. 9, n. 1, p 65-89, jan./abr. 2018. 
A Tabela 3 permite inferir que a literatura científica sobre a atuação do secretário executivo nas IFES articula-se em torno de questões que, juntas, fornecem uma visão panorâmica do tema: as motivações para seu ingresso nesse contexto; sua forma de inserção; o perfil e o panorama dos ocupantes do cargo; suas condições de trabalho; suas competências; suas contribuições em unidades administrativas e acadêmicas. Cabe mencionar que alguns dos trabalhos, sobretudo as dissertações, abordam mais de um tema mencionado no Quadro 3. Assim, a categorização foi feita com base nos seus aspectos mais evidentes.

\section{Principais perspectivas teóricas que fundamentaram as análises}

A perspectiva teórica que mais subsidiou os trabalhos sobre a atuação do secretário executivo nas IFES foi a Gestão por Competências (GpC) (Leal, 2014; Leal, Silva \& Dalmau, 2014; Leal \& Dalmau, 2014; Raviani, 2015; Souza, S. 2017). O interesse de tais pesquisas nesse modelo gerencial se manifesta como reflexo de um contexto socioeconômico mais amplo. Em nível internacional, a instituição de uma agenda político-econômica neoliberal favorece o surgimento de um conjunto de abordagens voltadas a aplicar os princípios do mercado e a lógica empresarial, baseados em competição e em resultados, na administração pública de vários países do mundo (Andion, 2012). No setor público brasileiro, a GpC emerge com a Nova Administração Pública (NAP), composta por "valores e princípios administrativos que configuram modelos de gestão (voltados para a eficiência, a descentralização e a excelência do serviço público)" (Andion, 2012, p. 8). A institucionalização da $\mathrm{GpC}$ nesse domínio se dá por meio da Política Nacional de Desenvolvimento de Pessoal (PNDP), que a define como forma para desenvolver a "gestão da capacitação orientada para o desenvolvimento do conjunto de conhecimentos, habilidades e atitudes necessárias ao desempenho das funções dos servidores, com vistas a alcançar dos objetivos da instituição" (Brasil, 2006). No entanto, os meios para operacionalizar esse modelo no âmbito das IFES permanecem obscuros, como demonstram alguns dos estudos de caso explorados, cujas instituições ainda não conseguiram adotar o sistema em sua totalidade.

Também, houve estudos que abordaram aportes teóricos relacionados à Administração Pública e à Administração Pública Brasileira (Custódio, Ferreira \& Silva, 2008; Faria \& Silveira, 2015; Oliveira \& Moraes, 2014; Souza, 2017). Foram tratados temas como o ingresso no serviço público e diferenças entre cargo público e função pública; paradigmas da 
Leal, F. G., Souza, S., \& Moreira, K. D. (2018).

Administração Pública (Patrimonialismo, Burocracia, Gerencialismo e Novo Serviço Público) e os atuais desafios da Gestão Pública Brasileira nas IFES.

Outro tema abordado nos referenciais dos estudos foi a Gestão Universitária. Vale destacar que, mesmo de forma indireta, esse foi um elemento comum a todos os trabalhos, visto que se tratam de estudos desenvolvidos no campo das IFES. No entanto, alguns trabalhos não abordam a mencionada temática individualmente. Destaca-se nos trabalhos de stricto sensu de Leal (2014), de Sousa (2014) e de Souza (2017) um aprofundamento sobre o tema, principalmente por se tratar de estudos que exigem tal característica e, também, pelo o que foi proposto. Cabe salientar que dos trabalhos emerge a questão do desafio de gerir um ambiente tipificado pela complexidade, a qual se manifesta intrinsecamente naquilo que se refere à natureza de tais instituições, além da estrutura, dos processos, do comportamento das atividades intelectuais, das produções e da transmissão do conhecimento (Meyer Jr., 2014).

Alinhado à Gestão Universitária, o estudo de Oliveira et al. (2016) trata dos editais dos concursos públicos para o ingresso do secretário executivo nas IFES. Em termos de referenciais teóricos, as autoras apenas acrescentam alguns outros estudos sobre o tema e as normativas sobre concursos. Outro trabalho que aborda o mesmo tema é o de Nunes (2014), no entanto, este se destaca pela abordagem teórica diferenciada, ou seja, a pesquisa derivou para matéria sobre o gênero do discurso utilizado nos editais de concursos de IFES para o Secretariado, embasada na teoria Bakhtiniana. Leal, Silva e Dalmau (2014), por sua vez, atêm-se às provas dos mencionados concursos, fundamentam suas análises na GpC.

Princípios da Qualidade de Vida no Trabalho (QVT) também são discutidos nos trabalhos (Oliveira, Minetti \& Oliveira, 2012; Oliveira, 2013). Os autores discorrem desde a essência da matéria, nascida como extensão da Qualidade Total, que hoje ocupa posição fundamental nas organizações (Vasconcelos, 2001), inclusive no setor público, até elementos que deveriam da teoria, como é o caso da ergometria. Faria e Silveira (2015) tratam do significado de trabalho e de teorias motivacionais, com foco na Teoria da Autodeterminação, cujas bases situam-se no estudo dos componentes de motivação intrínseca e de motivação extrínseca (Faria \& Silveira, 2015). É interessante observar que as teorias abordadas nos trabalhos verificados têm associação, não só por tratarem do secretariado executivo e da Gestão Universitária, mas por seguirem a linha de gestão de pessoas, na qual se incluem os temas de gestão por competências, significado de trabalho e qualidade de vida no trabalho, teorias motivacionais e a questão do ingresso nas instituições. 
Finalmente, referenciais teóricos sobre a internacionalização da educação superior, que a partir dos anos de 1990 adquiriu popularidade tanto em nível prático (como processo) quanto em nível teórico-empírico (como fenômeno), são abordados por Leal e Moraes (2014). Os autores adotam uma perspectiva crítica para tratar do tema, explicitando os obstáculos referentes à gestão da internacionalização em universidades de países periféricos e semiperiféricos, que tendem a inserir-se no contexto da educação superior mundial de maneira subordinada. Assim, os autores argumentam sobre a relevância de compreender se as instituições universitárias brasileiras públicas dispõem, nos quadros funcionais, de profissionais com competências para atuar naquilo que demanda a gestão das dimensões internacional, intercultural e global.

\subsection{Balanço da Literatura}

\section{Principais discussões e contribuições dos trabalhos}

Um balanço da literatura analisada permite apontar para as principais discussões evidenciadas nos estudos e suas contribuições para o estado do conhecimento sobre a atuação do secretário executivo nas IFES. Os seguintes aspectos são sintetizados:

Parte dos estudos problematiza o ingresso do profissional de secretariado executivo nas IFES, tanto no que se refere aos editais de seleção (Nunes, 2014 \& Oliveira et al. 2016) quanto em relação às avaliações (Leal, 2014; Leal, Silva \& Dalmau, 2014). Leal, Silva e Dalmau (2014) por exemplo, analisam as provas dos concursos públicos para o provimento do cargo, referentes ao período de 2010 a 2014, e inferem que essas instituições não têm considerado a formação do secretário executivo de maneira significativa nas provas e tampouco têm elaborado questões diretamente relacionadas a atividades constantes na descrição do cargo, exceto aquelas para as quais a Administração Pública prevê normas específicas em legislação. Outras limitações que os autores evidenciam são a pequena quantidade de questões diretamente relacionadas ao ambiente em que o profissional atuará e a ausência de instrumentos que avaliem habilidades e comportamentos. Ainda, no que tange à motivação para o ingresso no Serviço Público, Faria e Silveira (2015) verificam que os aspectos de estabilidade e segurança foram os fatores mais indicados pelos egressos da UFV como motivadores para ingressar no serviço público, seguidos de salários e benefícios. Boa 
Leal, F. G., Souza, S., \& Moreira, K. D. (2018).

parte dos respondentes também foi motivada pelos trabalhos e estágios que realizaram na área, no decorrer do curso, que foram determinantes para o desenvolvimento da motivação.

Também quanto à inserção do secretário executivo na IFES, alguns estudos apontam para o fato de muitas dessas instituições manterem em seus quadros ocupantes do cargo graduados em outras áreas, que foram favorecidos pela legislação e enquadrados à carreira ou aprovados em concursos cujos editais aceitavam graduados em Letras (Oliveira \& Moraes, 2014). Esse cenário parece mais problemático em algumas IFES do que em outras: enquanto Oliveira e Moraes (2014) verificaram que dos 45 secretários executivos da UFSM cinco têm formação em Secretariado, 29 são graduados em Letras e doze são enquadrados na carreira, Leal (2014) e Souza, S. (2017) constatam que a grande maioria dos ocupantes do cargo na UFSC têm formação na área. Essa conjuntura demonstra a influência da aplicação do Ofício Circular n. 015/2005, ou seja, da exigência da habilitação profissional para a posse no cargo.

No que concerne à atuação do profissional de secretariado executivo nesse ambiente, há estudos que sugerem a ausência de critérios para sua distribuição nos setores que compõem a estrutura organizacional (Leal, 2014; Souza, S. 2017). Leal (2014) reforça essa possibilidade diante da grande quantidade de secretários executivos que trocaram de setores na UFSC, a pedido. Quando questionados sobre suas motivações, os participantes de sua pesquisa apontam principalmente para o fato de "não exercerem atividades compatíveis com seu cargo e sua formação, o que os levava a sentirem-se desvalorizados e desmotivados" (Leal, 2014, p. 124). Complementarmente, Souza, S; (2017) verifica que as demandas apresentadas pelas unidades acadêmicas e administrativas são utilizadas como planejamento de pessoal para o cargo de secretário executivo na UFSC.

Ainda no que se refere à atuação do secretário executivo nas IFES, sobretudo as dissertações (por exemplo, Leal, 2014; Sousa, 2014; Souza, S. 2017) demonstram que esse profissional tem se inserido em todos os setores que constituem a estrutura universitária, tanto de natureza acadêmica quanto administrativa: secretarias de órgãos deliberativos, gabinete de reitoria, pró-reitorias/secretarias, direções de campi e de centros de ensino, programas de pósgraduação, departamentos de ensino e coordenadorias de curso, além de órgãos suplementares, como o hospital universitário. Destaca-se que alguns trabalhos manifestam preocupação com as condições do ambiente trabalho (Oliveira, Minetti \& Oliveira, 2012; Pereira, 2013) e, nesse sentido, dissertam sobre a qualidade de vida no trabalho e também, sobre a estrutura que as instituições oferecem em termos de recursos materiais para a atuação. 
Os resultados são positivos, visto que ambos os estudos destacam a preocupação das universidades pesquisadas em relação ao tema.

Observa-se que além de contribuírem para o entendimento da atuação do secretário executivo no contexto das IFES, os estudos analisados proporcionam conhecimentos que se apresentam como funcionais à gestão universitária e que podem fomentar discussões favoráveis ao estabelecimento de políticas, programas e ações relacionadas ao cargo, referentes a aspectos como: processo de seleção, lotação, aperfeiçoamento profissional e desenvolvimento de competências, entre outros. Os estudos que tratam dos concursos públicos, por exemplo, expõem limitações relacionadas tanto aos editais quanto às provas realizadas e apresentam uma série de recomendações para que eles mensurem, em maior grau, os conhecimentos requeridos para o bom desempenho de suas funções. Ainda, estudos como os de Ferreira (2011) e Souza S. (2017) apresentam a necessidade da contratação de maior número de profissionais de secretariado executivo no âmbito das instituições analisadas. Porém, conforme lembram Oliveira e Moraes (2014) e Souza, S. (2017), há que se observar a distribuição desses profissionais nas instituições, que, segundo as mencionadas pesquisas, devem ser lotados, prioritariamente, em setores considerados como unidades-chave (Gabinete da reitoria, pró-reitorias, direções de centros de ensino, dentre outros).

Uma preocupação central dos trabalhos é a questão das atribuições e das competências do secretário executivo no âmbito das IFES. Leal (2014) revela uma série de competências técnicas e comportamentais requeridas aos secretários executivos da UFSC. Entre as técnicas, a autora identifica aspectos como conhecimento dos trâmites, das rotinas administrativas, das normas e das resoluções da instituição; domínio do padrão culto da língua portuguesa; elaborar documentos claros e concisos com agilidade; utilizar recursos e softwares disponíveis para administrar dados e informações e capacidade de planejar as rotinas e as atividades do setor. Entre as comportamentais, destacam: responsabilidade; capacidade de adaptação; ética profissional e discrição; predisposição; saber comunicar-se com diferentes níveis hierárquicos; bom relacionamento interpessoal; equilíbrio emocional nas situações de conflito e saber trabalhar sob pressão; saber administrar a equipe de trabalho; delegação de atividades; boa administração do tempo; raciocínio lógico; bom senso e autonomia para tomar decisões. Souza, S. (2017) verifica competências bastantes similares na mesma instituição e destaca que, na visão de gestores de unidades-chave da UFSC, as competências comportamentais de comprometimento, organização e proatividade são as mais necessárias a esse profissional. Em relação às competências técnicas, tais gestores apontam para conhecimentos da estrutura e 
Leal, F. G., Souza, S., \& Moreira, K. D. (2018).

funcionamento da Instituição e das rotinas administrativas, incluindo-se as leis pertinentes. Raviani (2015), por sua vez, detecta como as competências mais necessárias para o trabalho dos ocupantes do cargo de três IFES paulistas: redação, comprometimento, trabalho em equipe, responsabilidade, assessoramento, conhecimento da instituição, ética, língua portuguesa, relacionamento interpessoal, controle de documentos, resolução de problemas e cooperação.

Em relação às possibilidades de que esse profissional contribua com a gestão universitária, os estudos identificam secretários executivos que atuam em áreas estratégicas e desenvolvem funções gerenciais, tais como planejamento e gerenciamento de processos organizacionais (Sousa, 2014; Leal, 2014; Souza, S. 2017). Nesse aspecto, Leal (2014) constata que secretários executivos lotados em setores da Administração Central e ocupantes de funções administrativas na UFSC tendem a desempenhar atribuições com maior nível de complexidade, como liderança de equipes, coordenação de recursos financeiros e gestão de bens, além de estarem mais inseridos nos processos decisórios. Leal e Moraes (2017), por sua vez, identificam uma série de convergências entre as competências do secretário executivo e as competências necessárias à gestão da internacionalização da educação superior e inferem que, ao menos na teoria, esse profissional apresenta condições de contribuir com o processo de internacionalização das IFES.

Embora os estudos apontem para diversas dificuldades inerentes à gestão do cargo e induzam à conclusão de que muitos dos secretários executivos não são bem aproveitados por essas instituições (Leal, 2014), eles também permitem inferir que esses profissionais se destacam e são reconhecidos por sua proatividade, capacidade de interpretação de situações, intervenção e tomada de decisão, dentre outros aspectos, representando possibilidade de aperfeiçoamento dos níveis de qualidade dos serviços prestados e de desenvolvimentos em termos de profissionalização da gestão universitária (Ferreira, 2011; Souza, S. 2017). Essa situação se manifesta, por exemplo, na percepção dos gestores quanto aos ocupantes do cargo na UFSC, que apesar de admitirem desconhecimento sobre as funções do cargo, relatam que as atividades de seu setor passaram a ser mais bem executadas quando um secretário executivo assumiu as funções (Leal \& Fiates, 2013).

Observa-se, portanto, que ainda que as IFES analisadas pelos estudos não estejam inteiramente preparadas para aproveitar o potencial de contribuição do secretário executivo em sua totalidade, o perfil desse profissional lhe permite atuar em níveis estratégicos da gestão universitária, inclusive junto aos gestores principais, desenvolvendo atividades 
complexas e de alta relevância para a universidade e para a sociedade na qual ela está inserida.

\section{Considerações Finais}

O objetivo deste artigo foi o de apresentar o estado do conhecimento sobre a atuação do secretário executivo na gestão das IFES. Para alcançá-lo, desenvolveu-se uma pesquisa bibliográfica, baseada em critérios de revisão sistemática de literatura, nos artigos de periódicos e trabalhos stricto sensu sobre o tema de interesse. Evidenciou-se que o interesse teórico-empírico dos estudos analisados se articula em torno dos seguintes aspectos: as motivações para seu ingresso nesse contexto; sua forma de inserção; o perfil e o panorama dos ocupantes do cargo; suas condições de trabalho; suas competências; suas contribuições em unidades administrativas e acadêmicas.

Embora quantitativamente pequena, a literatura abrangida pelo recorte da pesquisa permite obter um panorama geral da atuação do secretário executivo no contexto das IFES e reflete a complexidade adjacente ao tema, que se intensifica, por um lado, pelas tensões da gestão universitária pública e, por outro, pelas características do perfil desse profissional. Os conhecimentos proporcionados pelos estudos contribuem tanto para o entendimento da atuação do secretário executivo no contexto das IFES quanto podem auxiliar no aperfeiçoamento da gestão universitária, uma vez que apresentam diagnósticos e recomendações capazes de fomentar discussões favoráveis ao estabelecimento de políticas, programas e ações relacionadas ao cargo, com vistas ao melhor aproveitamento do seu potencial de contribuição. O cenário reforça, também, a relevância de pesquisas no campo do secretariado executivo. Certamente, com o desenvolvimento e a implementação de programas ou cursos stricto sensu de secretariado, o impacto do secretariado como campo de pesquisa haverá de ser relevante.

Este estudo não objetivou desenvolver análises relativas à qualidade dos trabalhos contemplados pelo recorte da pesquisa. No entanto, tendo em vista as lacunas evidenciadas, podem-se apontar algumas recomendações de estudos futuros sobre a atuação do secretário executivo nas IFES: 1) uso de referenciais mais críticos e interpretativos, que contribuam para o desenvolvimento de teorizações relacionadas ao tema e que permitam olhar para os fenômenos de interesse por meio de "lentes complementares"; 2) melhor articulação com as teorias de gestão pública e com as particularidades da gestão universitária pública brasileira; 
Leal, F. G., Souza, S., \& Moreira, K. D. (2018).

3) exploração de metodologias menos ortodoxas, como a etnografia e a observação participante; 4) consideração de estudos prévios sobre o tema, que permitam avançar sobre o que já foi desenvolvido; e 5) triangulação de dados coletados de diversas fontes, com vistas a obter panoramas mais amplos da realidade que se almeja conhecer.

\section{Referências}

Andion, C. (2012). Por uma nova interpretação das mudanças de paradigmas na administração pública. Cadernos Ebape.BR, 10(1), Rio de Janeiro.

Brasil. (1996). Lei n. 9.394, de 20 de dezembro de 1996. Diário Oficial [da] República Federativa do Brasil, Brasília, 23 dez.

. (2005). Lei n. 11.091, de 12 de janeiro de 2005. Diário Oficial [da] República Federativa do Brasil, Brasília, 13 jan.

. (2006). Decreto n. 5.707, de 23 de fevereiro de 2006. Diário Oficial [da] República Federativa do Brasil, Brasília, 24 fev.

. (2018). Decreto n. 9.262, de 9 de janeiro de 2018. Diário Oficial [da] República Federativa do Brasil, Brasília, 10 jan.

Custódio, C.; Ferreira, F. \& Silva, L. (2008). O profissional de secretariado na gestão pública: um estudo de caso na faculdade de medicina da Universidade Federal do Ceará. Secretariado Executivo em Revista, 4.

Dias, A.; Schmidt, C. \& Sanches, F. (2016). A pesquisa no secretariado executivo: um olhar para os periódicos científicos. In: Antunes, C., \& Nascimento, E. O conhecimento científico em Secretariado. João Pessoa: Ideia.

Durante, D. (2016). Produção científica em secretariado executivo: características e relevância dos trabalhos publicados no encontro nacional acadêmico de secretariado. In: Antunes, C., \& Nascimento, E. O conhecimento científico em Secretariado. João Pessoa: Ideia.

Durante, D. \& Pontes, E. (2015). Produção intelectual em secretariado executivo: estudo na Revista de Gestão e Secretariado. Revista de Gestão e Secretariado, 6(1), 23-47. 
Etzioni, A. (1967). Organizações complexas: um estudo nas organizações em face dos problemas sociais. São Paulo: Atlas.

Faria, E. \& Silveira, T. (2015). Os fatores que influenciam os egressos do curso de Secretariado Executivo trilíngue da Universidade Federal de Viçosa a ingressarem no serviço público. Revista de Gestão e Secretariado - GeSec, 6(1), 48-73.

Ferreira, F. (2011). A atuação do secretário executivo no setor público: o caso da Universidade Federal do Ceará. Dissertação de mestrado, Universidade Federal do Ceará.

GeSec (2017). Revista de Gestão e Secretariado. Recuperado em 8 julho, 2017, de < https://www.revistagesec.org.br/secretariado>.

Kim, T. (2017). Academic mobility, transnational identity capital, and stratification under conditions of academic capitalism. Higher Education, 73(6), 981-997.

Leal, F. (2014). Competências secretariais requeridas pela Universidade Federal de Santa Catarina. Dissertação de mestrado. Florianópolis, Universidade Federal de Santa Catarina.

., \& Dalmau, M. (2014). Análise das competências secretariais requeridas pela UFSC em comparação ao perfil profissiográfico do secretário executivo. Revista de Gestão e Secretariado, 5(3), 143-174.

., \& Fiates, G. (2013). Competências dos secretários executivos de uma universidade pública federal: uma análise a partir da perspectiva dos gestores. Revista de Gestão e Secretariado, 4(3), 30-57.

Silva, A. \& Dalmau, M. (2014, dez.). Análise das avaliações dos concursos públicos realizados pelas IFES para o cargo de secretário-executivo sob a ótica da Gestão por Competência. Revista de Ciências da Administração, 191-207, dez.

Leal, F. \& Moraes, M. (2017). Perspectivas de atuação do secretário executivo na gestão da internacionalização da educação superior. Revista de Gestão e Secretariado, 8(1), 138167. 
Leal, F. G., Souza, S., \& Moreira, K. D. (2018).

Maçaneiro, M. \& Kuhl, M. (2013). Estado da arte e o rumo do conhecimento científico em secretariado executivo: mapeamento e análise de áreas de pesquisa. Revista de Gestão e Secretariado, 4(3), 157-188.

Martins, C. et al. (2015). A busca da cientificidade do Secretariado no contexto brasileiro: Aspectos históricos e atuais. Congresso Internacional de Secretariado e Assessoria. Porto: Portugal.

Meyer Jr., V. (2014). A prática da administração universitária: contribuições para a teoria. Revista Universidade em Debate, 2(1), 12-26.

, V. \& Lopes, M. C. B. (2015, jan-mar.). Administrando o imensurável: uma crítica às organizações acadêmicas. Cadernos Ebape.BR, 13(1), 40-51, jan.-mar.

Ministério da Educação - MEC. (2005). Ofício Circular n. 015/2005/CGGP/SAA/SE/MEC, de 28 de novembro de 2005. Apresenta a descrição dos cargos técnico-administrativos em educação.

Monteiro, C., Crotti, K., \& Santos, C. Encontro Nacional Acadêmico de Secretariado Executivo - Enasec: Um Estudo Bibliométrico. Revista de Gestão e Secretariado, 7(3), 123-149.

Muller, R. \& Sanches, F. (2014). Pesquisa acadêmica em secretariado executivo: um estudo de caso na Revista Expectativa. Revista Expectativa, 13(13), 9-28.

Nunes, W. (2014). Concurso público: uma análise dos editais no processo seletivo de secretários executivos nas instituições federais de ensino. Revista do Secretariado Executivo, 10, 105-118.

Oliveira, L. \& Moraes, G. (2014). O panorama do cargo de Secretário Executivo em uma instituição federal de ensino superior e as implicações da Lei n. 11.091/2005. Revista de Gestão e Secretariado - GeSec, 5(2), 49-71.

Oliveira, L., et al. (2016). Os concursos para o cargo de Secretário Executivo nas instituições federais de ensino superior. Revista de Gestão e Secretariado - GeSec, 7(3), 202-225. 
P., Minetti, L. \& Oliveira, L. (2012). Qualidade de vida no trabalho: um enfoque no profissional de Secretariado Executivo de uma instituição federal de ensino superior. Revista de Gestão e Secretariado-GeSec, 3(2), 87-105.

Pérez, L. (2015). Revisión sistemática de la producción española sobre rendimiento académico entre 1980 y 2011. Revista Complutense de Educación, 27(1), 119-139.

Pinheiro, V. (2013). Condições de trabalho do profissional de Secretariado Executivo no setor público: um estudo de caso na Universidade Federal do Ceará. Dissertação de mestrado, Fortaleza, Universidade Federal do Ceará.

Raviani, C. (2015). Competências individuais: secretários executivos das universidades federais do estado de São Paulo. Dissertação de mestrado. Osasco, Universidade Federal de São Paulo.

Sampaio, R. F. \& Mancini, M. C. (2007). Estudos de revisão sistemática: um guia para síntese criteriosa da evidência científica. Revista Brasileira de Fisioterapia, São Carlos, 11(1), 83-89.

Sanches, F.; Schmidt, C., \& Dias, A. (2014). Os avanços da pesquisa em secretariado executivo: uma análise dos periódicos científicos nacionais. Revista Capital Científico, $12(4), 1-16$.

Seeber, M. et al. (2016). Why do higher education institutions internationalize? Higher Education, 72(5), 685-702.

Siekierski, P., \& Lima, M. C. (2016, set.). Brain drain/drain gain e inovação. O estado de arte sobre a questão. XL Encontro da Anpad. Costa do Sauípe/BA - 25 a 29 de setembro.

Sousa, E. (2014). Perfil e realidade laboral do Secretário Executivo no contexto das universidades públicas federais brasileiras. Dissertação de mestrado. Florianópolis, Universidade Federal de Santa Catarina.

Souza, I. M. (2010). Contribuições para a construção de uma teoria de gestão universitária. In: Silveira, A., \& Domingues, J. C. de S (Orgs.). Reflexões sobre administração universitária e ensino superior. Curitiba: Juruá. 
Leal, F. G., Souza, S., \& Moreira, K. D. (2018).

Souza, S. (2017). O quadro de pessoal do cargo de secretário executivo na Universidade Federal de Santa Catarina. Dissertação de mestrado. Florianópolis, Universidade Federal de Santa Catarina.

Stake, R. (2011). Pesquisa qualitativa: estudando como as coisas funcionam. São Paulo: Penso.

Vasconcelos, A. F. (2001). Qualidade de vida no trabalho: origem, evolução e perspectivas. Caderno de pesquisas em Administração, 8(1), 23-35. 